\title{
ASSESSMENT OF INTERCHANGEABILITY OF POSTAL SERVICES IN TERMS OF VALUE ADDED
}

This paper is focused on the issues of interchangeability of postal services. It presents the main terms related to the issues, the relevant legislation on postal services and describes the different aspects of the assessment of postal services interchangeability. It focuses mainly on the assessment of interchangeability of postal services in terms of value added. The aim of the article is to apply the method of determining the added value in assessing the interchangeability of postal services. The paper refers to a particular application of the proposed procedure and quantitative output of interchangeability evaluation of the postal services.

Keywords: Value added, interchangeable postal services, use value, liberalization.

\section{Introduction}

Recently, the term "liberalisation" has become widespread in the postal sector. The main issues in the liberalisation process are the need to guarantee the universal service and finding a new way of financing the universal service. Last legislation in the postal sector in the Slovak Republic requires the use of a compensation fund to ensure funding the forced costs from providing the universal service. Contributors to the compensation fund are all the providers of interchangeable postal services. The main problem of this legislation is a decision and, thus the answer to the question when it comes to interchangeable service [1], [2] and [3].

\section{Assessment of interchangeability}

According to $\S 4$, Section 1, of the Postal Services Act, interchangeable postal service is a postal service that can be considered from the user's point of view to be the service that belongs to the range of a universal service by being interchangeable to a sufficient degree with the universal service [4] and [5]. Simply, we can say that the interchangeable service is a service provided by a postal service provider which is not the universal service provider and the service is similar to the service from the range of universal services. These services may be similar/interchangeable from different perspectives. According to the act, assessment of interchangeability is conducted from the following perspectives:
- content of postal service,

- purpose and usage of postal service,

- price of postal services,

- added value of postal service.

From some perspectives, the assessment of interchangeability is quite obvious, such as the price of postal service. Therefore, the explicit aspects are considered as first when assessing the interchangeability. The assessment based on the value added approach is used just in the case when the postal service is considered as interchangeable from all other perspectives [6] and [7].

\subsection{Assessment of interchangeability from the value added perspective}

Value added can generally be assessed on the basis of evaluation of customer value. The notion of value is neither absolute nor objective. It is always subjective because every customer has individual values, depending on his/her needs. In essence, the customer value is divided into three categories: exchange value (represented by price), use value (represented by total utility) and emotional value [8].

The exchange value is the value expressed in the price which the postal company is willing to provide the postal service for and a postal customer is willing to pay for it. The exchange value is created in the market at the point where supply meets the

\footnotetext{
* Karol Achimsky, Lukas Achimsky, Petra Kunertova

Department of Communications, Faculty of Operation and Economics of Transport and Communications, University of Zilina, Slovakia,

E-mail: karol.achimsky@fpedas.uniza.sk
} 
demand - postal operators and their customers, while both of these entities are willing to proceed an exchange for this price.

The use value (or value-in-use) refers to a value that a postal service generates for a specific owner under a specific use.

Emotional value is represented by the individual satisfaction (complacency), emotional and intangible aspects (money customers hardly spend their money, time - the value of time is considered to be higher than the value of money), effort - the customer must put a physical effort to obtain a postal service, psychological stress - involves the need to deal with the postal service provider, waiting for the provision of services, filling out forms, the need to understand the new procedures, the need to adapt to new things and situations.

As it was previously mentioned, the emotional value is very subjective, because each customer is different. For this reason, we will take into account, while quantifying the value added, particularly the use value expressed in the total utility (TU) and the exchange value expressed in the service price $(\mathrm{P})$.

\subsection{Quantification of value added}

Customer value added $=$ proportion of total utility of postal services and prices/tariffs for postal service:

$$
V A=T U / P
$$

$$
\begin{aligned}
& \text { VA - value added } \\
& \text { TU - total utility } \\
& \text { P - price }
\end{aligned}
$$

The total utility is a set of benefits that the customer expects from the postal service. Price represents a financial value that the customer must expend in relation to evaluating, obtaining and using the postal services [1].

\subsection{Basic factors of customer utility}

Factors of utility for the customers primarily include:

- warranty (content and scope of warranty result in gaining the customer trust to the postal company and the postal services offered by the company);

- reliability in the provision of postal services (a low number of complaints, the postal company's good image in the eyes of customers);

- speed of providing the postal service ( $\mathrm{D}+\mathrm{x}$ );

- quality of provided services attributed to the postal company based on the quality certificates, e.g. ISO 2000, etc.;

- accurate and timely information (provided to the customer before, during and after the provision of postal service);
- customer care and respect (professional and dignified customers treatment while providing the postal services, in terms of trust, courtesy, etc.);

- convenience (the simplicity of postal service provision - spatial and temporal availability of postal services, ease of mailing conditions, etc.).

\subsection{Procedure for assessment of the use value}

Assessment of the use value may be determined by using a variety of theoretical methods and procedures. As a procedure for assessment of the use value, which can be applied in testing the interchangeability of postal services, we will describe a procedure that follows the next steps:

A. Establishing evaluation criteria,

B. Establishing criteria weights,

C. Evaluating alternatives,

D. Aggregating partial use values,

E. Selecting the best alternative.

\section{A. Establishing evaluation criteria}

For the development of criteria arising from the foundations of utility theory and the logic of mathematical model, basic requirements of criteria such as relevance, integrity, independence, discrimination and compensation must be met. Relevance can be understood as a significance of the various criteria and from the completeness perspective, all relevant criteria have to be taken into account. We must also ensure that the criteria in their remarks do not affect each other (correlating characters must be assigned to the superior characters), which will be ensured by the requirement for independence. Discrimination says that the criteria manifestation of the various alternatives have to be reflected in different results. Compensation means the linking of criteria, so that "better" one in the first criterion must compensate "worse" one in the second criterion.

For the development of evaluation criteria in terms of postal services, it is needed to be aware of these essential requirements:

- criteria cannot be determined in general, but only in relation to the issue of interchangeability of postal services;

- criteria must be derived from superior (strategic) objectives fulfilling the Postal Services Act;

- criteria shall be divided as long as they can be clearly determined.

\section{B. Establishing criteria weights}

After the establishment of evaluation criteria, which have been determined on the basis of the above requirements, we can specify the weights for the criteria. Criteria weights are characterized by the following: 
- they assess the importance of each criterion of interchangeability of postal service,

- since there are too many criteria for the direct assignment of weights, they can be arranged in a target hierarchy, and then group-weighted,

- $\quad$ sum of the factors of one group $=1$,

- absolute weight of one character (absolute partial utility) is calculated as the multiplication of specific weights of the degree (relative partial utility) and all superior specific weights,

- predicted costs of the postal service can be directly evaluation criterion and their value can represent the use value, as a final ranked dimension is the profit.

\section{Evaluating alternatives}

In doing so, it is an assessment of interchangeability of postal services depending on how far the developed characters relevant for the decision are. We must realize that the quantitative and qualitative variables must be transformed into numerical values with the same dimension in all evaluation criteria.

\section{Aggregating partial use values}

- Aggregating the use values must meet the following requirements:

- total utility of each postal service can be derived from the weighted partial utilities,

- numerical values (scores) are multiplied by the criteria weights and the results are summed,

- sometimes it is preferable to use multiplication instead of addition, it is thus possible to evaluate the postal services with low scores in some respects, while a low score for addition connections can be significantly compensated by large numbers,

- K.O. criterion is taken into account when the final result is equal to zero.

\section{E. Selecting the best alternative}

After the realization of all the previous steps for assessing the use value, we can proceed to the final step, which definitely evaluates the best alternative from the group of assessed postal products and services. This part of the evaluation process allows us to use the total use values of the assessed postal products and services to derive the final ranking of examined alternatives.

Due to the subjective assessment and weighting of criteria, and as a result of not always theoretically explainable transformation of characteristics to the numerical values, "control of assurance" should be proceeded.

Method of "equivalency test" compares the different criteria which have diverse results, and submits the abstract, weighted use values back to the specific characteristics of characters [1].

\section{Example on the assessment of the use value}

For a better understanding how to decide on the interchangeability of the two services based on the assessment of the added value, we will give an example, which is provided (see Table 1). This will be an evaluation of the interchangeability of a postal service provided by alternative postal operator and a postal service from the scope of universal services provided by the Slovak Post - the universal service provider. From the content perspective, the service is interchangeable with the service " $1{ }^{\text {st }}$ Class Parcel" provided by the Slovak Post. We will be considering the interchangeability of these two services in terms of added value.

\section{A. Establishing evaluation criteria}

In this case, we established the following evaluation criteria:

1. Ensuring the safety of postal items.

2. Appropriate conduct of employees.

3. Meeting the agreed conditions (speed of delivery of the item).

4. Process simplicity of the service.

5. Spatial and temporal availability of post offices and mailboxes.

6. Wait time.

7. Availability of information about the products and services.

8. Complaint handling.

9. Additional services.

We assigned the different quality levels to the specific criteria. We used the levels that are common in practice and that are characteristic for a given criterion such as ensuring the safety [9]:

- no guarantee against loss,

- guarantee up to the level of the difference,

- guarantee up to the price level,

- guarantee up to the multiplied price.

\section{B. Establishing criteria weights}

Then we identified the weights of each criterion according to a survey on customer satisfaction with the Slovak Post conducted in 2008. Those criteria that were not included in the survey were linked with the weights based on the expert estimation. Of course, the researcher could use the results of his own survey.

We assigned percentages to the qualitative levels of individual criteria according to their relevance to the customer so that the sum of the percentage of options for each criterion is equal to one hundred per cent.

We have to take into account the different opinions among ordinary customers who use postal services in a small volume (retail customers) and the customers who regularly use postal services in a large volume (corporate customers). These two groups of customers assign different weights to each criterion. For this reason, we divided the weights into two groups:

- retail customers - SU (small user),

- corporate customers - LU (large user). 


\section{COMMNICaIIONS}

Calculation of the total utility of selected postal services for the purposes of evaluation of interchangeability

of postal services (concept)

Table 1

1st Class Parcel - Day definite

1. Ensuring the safety of postal iten

No guarantee against loss

Guarantee up to the level of the difference

Guarantee up to the price level

Guarantee up to the multiplied price

2. Appropriate conduct of employees

Without independent evaluation

With independent evaluation

With published independent evaluation

3. Meeting the agreed conditions (speed of delivery of the item)

Without independent evaluation

With independent evaluation

With published independent evaluation

4. Process simplicity of the service

averagely up to 1 minute

averagely up to 2 minutes

averagely over 2 minutes

5. Spatial and timely availability of post offices and mailboxes

\begin{tabular}{|c|c|}
\hline Spatial avallability (branch network) & $40 \%$ points \\
\hline & $501+$ \\
\hline & $101-500$ \\
\hline & 11.100 \\
\hline & $0-10$ \\
\hline Timely availability & $60 \%$ points \\
\hline & $18-24$ \\
\hline & $12 \cdot 18$ \\
\hline & $6-12$ \\
\hline & 0.6 \\
\hline
\end{tabular}

\begin{tabular}{l} 
6. Wait time \\
\hline Wime the branch \\
\hline
\end{tabular}

$0-3 \mathrm{~min}$

\begin{tabular}{|lc|}
\hline & $0-3 \mathrm{~min}$. \\
\hline & $3-6 \mathrm{~min}$. \\
\hline Wait time for the courler & $6-9 \mathrm{~min}$. \\
\hline & $9+\mathrm{min}$. \\
\hline & $0-1$ hod. \\
\hline & $1-2$ hod. \\
\hline & $2-3$ hod. \\
\hline & $3+$ hod.
\end{tabular}

7. Availability of information about the products and services

physically at the branch

by phone

8. Handling of complaints

Guarantee of complaint handiling within the period at least 5 days shorter than the statutory deadiline

Free information about the complaint

9. Additional services

cash on delivery

insurance

fragile

bulky

telephone notice

reply service

Cancelllation of sent consignment

Cancellation of dellvered consignment

not to impose

store $X$ days

not to deliver

not to return

Poste restante

change of address

back to

exclusion substitute the consignee

extension of the time limit for delivery

time forwarding

delivery to another address for the recipient's request

mandate

denial of receipt of the shipment

repeated delivery to the recipient's request

provide information about the lodging of shipment

provide information about the dellvery of an item

provide information on Tracking

depreciation posting receipts

confirmation of the consignment

packaging

non-standard pick-up and delivery

Go Green

payment, billing options

\begin{tabular}{l|l|l|l|l|l|l|l} 
Weights - SU & Weights - LU & conv. SU conv. LU & SP & AO & Utility SP & Utility AO \\
\hline
\end{tabular}

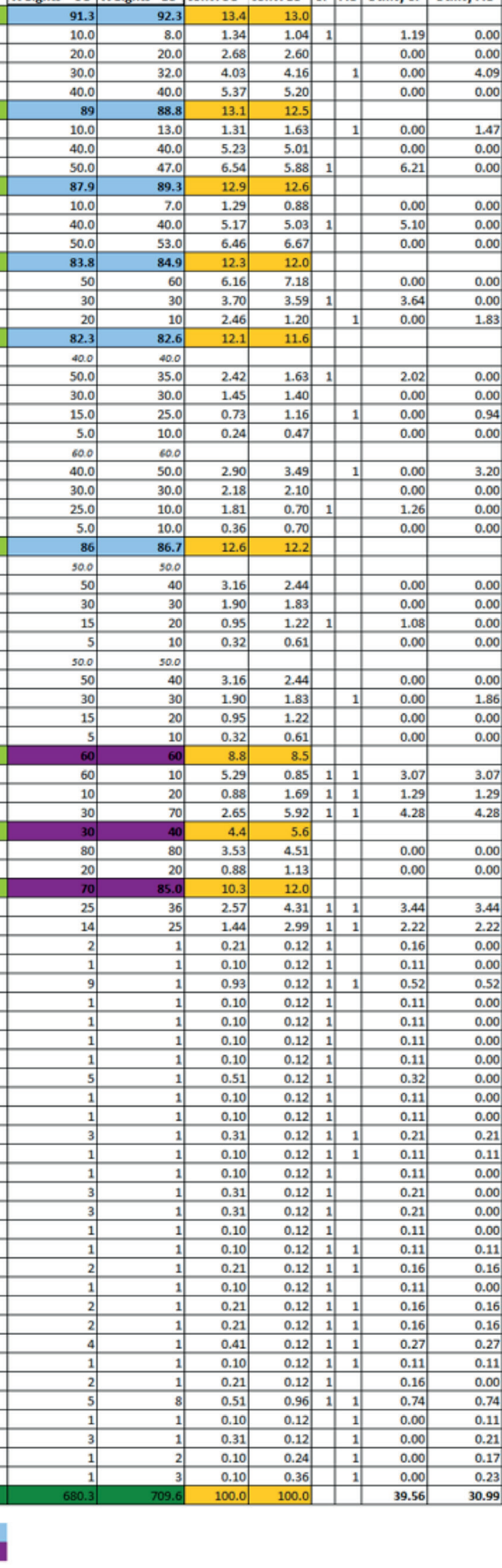




\section{Evaluating alternatives}

The next step is a numerical expression of the for the individual criteria and their options. First, it is necessary to convert the individual criteria on an equal basis. This is achieved as follows:

$$
\text { conv. SUILU }=\frac{x}{\sum x} \times 100 \%
$$

conv. $S U / L U$ - weights converted on an equal basis $x$ - weights of the individual criteria

It is also necessary to quantify the weights for the various options of criteria. We will obtain the result by the following calculation:

$$
Y=\frac{y}{\operatorname{conv} \cdot S U / L U} \times 100 \%
$$

conv. SU/LU - criterion weight

$y$ - significance of a given option of a given criterion expressed as a percentage

$Y$ - converted weight of a given option of criterion

\section{Aggregating partial use values}

To determine the individual use values, we must first determine which options of the individual criteria are met by the postal operators. One of these operators is the universal service provider and the other is the postal operator whose service is being assessed whether it is interchangeable or not. In our case, the Slovak Post represents the only universal service provider and unnamed company represents an alternative provider of postal services. We assigned a value of one to the option which was met by a given enterprise.

Consequently, the value of utility (U) for a given criterion and a given postal company is calculated as a sum of arithmetic averages of the converted weights of a given option of criterion for retail and corporate customers (the calculation is not presented in Table 1).

$$
U=\sum \frac{Y_{S U}+Y_{L U}}{2}
$$

$Y_{S U} Y_{L U}$ - converted weight of a given option of criterion $U$ - utility of the specific criterion

Final value of total utility (TU) of the compared services will be quantified as a sum of the utilities of single criteria.

$$
T U=\sum U
$$

$U$ - utility of the specific criterion

$T U$ - total utility

\section{E. Selecting the best alternative}

In our case, the total utility of the service " ${ }^{\text {st }}$ Class Parcel" provided by the Slovak Post is 39.56 points. For similar service provided by the alternative operator, the total utility is 30.99 points.

Based on the result, it would be logical to choose the service " $1{ }^{\text {st }}$ Class Parcel" provided by the Slovak Post.

\section{Conclusions}

To quantify the value added of services, we need to divide the total utility (Table 1 row "Total"), according to the above equation for calculating value added (1), by the price and then assess the interchangeability.

This division is necessary especially in cases when the total value of utility of alternative operator exceeds several times the value of the total utility of the universal service provider. In our case it is not necessary, since our results show that the value of the total utility of assessed postal service of alternative postal operator is even smaller than value of the total utility of the postal service from the area of universal services.

In our case, it is clear that it is the interchangeable service because the total utility of the service provided by the universal service provider is higher than the total utility of the similar service provided by the assessed company. So we cannot state that the assessed postal service of alternative operator has a significantly higher value added comparing to the service provided by the Slovak Post.

By the example of calculating the total utility of postal services and its interpretation, we have demonstrated the application of the method of determining the added value in assessing the interchangeability of postal services and thus we achieved the main objective. However, the results of the total utilities of services are not always so clear. In that case, it is necessary to calculate the value added. There may also be a problem when the value added of the service provided by the assessed postal company is higher than a value added of a similar service provided by the universal service provider. In that case, it would be necessary to decide how much the added values have to differ to become irredeemable services. There are several decision options. The exact value of the ratio or the difference for the calculated values added of compared postal companies would have to be determined by a regulatory authority for the postal sector in a given country.

This methodology quantifying the value added is intended primarily for postal sector regulator, which is the main authority in the evaluation of interchangeability of postal services as well as for postal operators themselves. The proposed solution also paves the way for a more detailed specification of the monitored criteria or more accurate determining the proportional 


\section{COMMNICOIIONS}

characteristics of utility perceived by customer according to type of customer.
This procedure may also serve as a guide for solving the issues of the quantification and comparison of value added in services in general.

\section{References}

[1] UNIVERSITY OF ZILINA: Solution of Problematic with Interchangeable Pservices, Including the Development of Methodologies for Assessing the Interchangeable Postal Services (in Slovak), project, No. 117, 2011.

[2] ACHIMSKY, K., ROSTASOVA, M., ACHIMSKA, V., HNATOVA, Z., KOLAROVSZKI, P.: Research of Using Alternative Financing Mechanisms of the Universal Postal Service in Slovakia after the Abolition of the Postal Reservation (in Slovak), 2007.

[3] CERP: Working Group Economics PT Universal Service and its Financing, 2008.

[4] Act No. 507/2001 Coll of. on Postal Services, as Amended (in Slovak), 2001.

[5] Act No. 324/2011 Coll of. on Postal Services and on Amendments to Certain Laws (in Slovak), 2011.

[6] PRU: Postal license No. 589/001/2004 (in Slovak), 2004.

[7] WIK-Consult GmbH: The Role of Regulators in a More Competitive Postal Market. Final Report. [online database] September 2011 [cit. 29. September 2013] Available at: http://ec.europa.eu/internal_market/post/doc/studies/2009-wik_regulators.pdf

[8] Economic portal EuroEkonóm.sk: The Value and Value Perceived by Customer (in Slovak). The Paper, [online database], September 2011 [cit. 30. September 2013] Available at: http://www.euroekonom.sk/obchod/predaj/hodnota-a-hodnota-vnimana-zakaznikom/

[9] HRNCIAR, M., GANOVA, J., MIKUSOVA, A.: Survey of Customer Satisfaction of the Slovak Post, project, 2008. 